\title{
Correlation of Serum Interleukin-6, TNF- $\alpha$, Procalcitonin and Leukocyte Count in Patients with Suspected Sepsis
}

\author{
Erfina Lim, Jusak Nugraha \\ Department of Clinical Pathology, Faculty of Medicine, Airlangga University/Dr. Soetomo Hospital Surabaya, Indonesia. \\ E-mail: e2dreams_na@yahoo.com
}

\begin{abstract}
Sepsis is a cause of non-cardiac death in the hospital. Early and rapid diagnosis of septic patients is a challenge to increase the expectancy of life. IL- 6 and TNF- $\alpha$ are groups of pro inflammatory cytokines that initiate an initial inflammatory response. Procalcitonin is a specific marker of bacterial infection. This study aimed to analyze the correlation of serum cytokine IL-6, TNF- $\alpha$, procalcitonin and leukocyte count in suspected sepsis patients. This was a cross-sectional observational study consisting of 45 patients with suspected sepsis with procalcitonin level $>0.5 \mathrm{ng} / \mathrm{mL}$. Procalcitonin level was measured with Enzyme-Linked Fluorescent Assay (ELFA) (VIDAS), IL- 6 and TNF- $\alpha$ levels were measured with the U-CyTech Human Elisa kit (Bioscience, INC) and leukocyte counts were measured with SYSMEX-XN 1000. It was found in this study that IL-6 levels ranged in $0 \mathrm{pg} / \mathrm{mL}-73.29 \mathrm{ng} / \mathrm{mL}$ (mean $29.43 \mathrm{ng} / \mathrm{mL}$ ), TNF- levels were $0 \mathrm{pg} / \mathrm{mL}-390.5 \mathrm{pg} / \mathrm{mL}(\mathrm{mean}$ $27.62 \mathrm{pg} / \mathrm{mL}$ ), and the mean value of leukocytes was $20,139 / \mu \mathrm{L}$. There was no correlation between leukocyte counts with IL-6 $(p=0.798$ and $r=0.040)$, TNF- $\alpha(p=0.304$ and $r=-0.160)$, and procalcitonin $(p=0.323$ and $r=0.154)$. There was no correlation between IL- 6 levels with TNF- $\alpha$ levels $(p=0.871$ and $r=-0.025)$, and procalcitonin levels $(p=0.466$ and $r=0.112)$. There was a weak negative correlation between TNF- $\alpha$ level and procalcitonin levels $(p=0.006$ and $r=-0.403)$ and there was a weak negative correlation between procalcitonin and TNF- $\alpha$ levels in suspected sepsis patients.
\end{abstract}

Keywords: Sepsis, procalcitonin, IL-6, TNF- $\alpha$

\section{INTRODUCTION}

One of the global healthcare problems is sepsis,which can cause organ dysfunction, due to whole-body inflammation in response to microbial infection. ${ }^{1}$ The incidence of sepsis in Dr. Soetomo Hospital Surabaya has increased in 2014 from 2446 to 2936 (Based on medical records of Dr. Soetomo Hospital in 2015).

Early diagnosis and appropriate therapy in sepsis is a challenge in the emergency room and ICU. Culture remains the gold standard for the diagnosis of sepsis; however, it requires a longer process. Various therapeutic strategies are known to increase the life expectancy of septic patients; therefore, a fast and accurate diagnosis is needed. ${ }^{2}$

Various markers of sepsis, including CRP, TNF- $\alpha$, IL-1, IL-6, IL-8, and procalcitonin have been investigated to determine the ability to distinguish SIRS from sepsis. Some researchers question the diagnostic accuracy of procalcitonin measurement. However, with inconsistent and various results, it is not easy to distinguish between SIRS and sepsis, despite the use of procalcitonin. ${ }^{1,3,4}$
IL- 6 and TNF- $\alpha$ are cytokines that play an important role in the acute phase response and are a group of proinflammatory cytokines that initiate an initial inflammatory response. ${ }^{5}$ These cytokines result in fever and are not derived from bacterial components known as endogenous pyrogens. IL- 6 and TNF- $\alpha$ also function by affecting the hepatocytes, bone marrow, endothelium, hypothalamus, fat, muscle, and dendritic cells. TNF- $\alpha$ is the main mediator of the immune response to Gram-negative bacteria. IL- 6 has been considered a cytokine whichpossesses pro-inflammatory and anti-inflammatory substances. IL- 6 plays an important role in the cellular and humoral immune response. ${ }^{5}$

The study by Muller et al. suggested that procalcitonin was more reliable to be a sepsis marker than CRP, IL-6 and lactate levels. Procalcitonin was better to distinguish SIRS from septic patients, followed by IL- 6 and II-8. Selberg et al.suggested that procalcitonin, IL-6, and C3a levels were more reliable parameters for differentiating sepsis and SIRS compared to CRP. ${ }^{4}$

To date, there has been no study performed in Dr. Soetomo Hospital to determine the correlation 
between IL-6, TNF- $\alpha$ and leukocytes count in the serum of patients with high procalcitonin levels. Based on the explanation above, this research needs to carried out to determine the correlation between procalcitonin, IL-6, TNF- $\alpha$, and leukocytes count in patients with suspected sepsis.

\section{METHODS}

This study was an observational analytic research with a cross-sectional approach using the serum of suspected sepsis patients with $\mathrm{f}$ high procalcitonin levels (>0.5 ng/dL). The serum was stored at $-70^{\circ} \mathrm{C}$ in aliquots. Measurement of IL- 6 and TNF- $\alpha$ levels were performed using U-cyTech Human IL-6 ELISA kit and U-cyTech Human TNF- $\alpha$ ELISA kit (Biosciences, Inc), respectively. Meanwhile, the measurement of procalcitonin level was performed with the ELFA method $\left(\mathrm{VIDAS}^{\mathrm{TM}}\right)$. The sample size was 45 serums randomly collected from male and female patients who were measured the procalcitonin levels in the Clinical Pathology laboratory of Dr. Soetomo Hospital Surabaya from January 2018 - April 2018.

Statistical analysis was performed using SPSS 22.0. One-sample Kolmogorov-Smirnov test was performed to determine the sample distribution and Spearman correlation test was used with $p$-value $<0.05$ and a confidence interval of $95 \%$.

Quality control aimed to ensure the reliability of the audit results. Quality control before the ELISA examination in our study was carried out through checking the expired date, lot numbers for each kit, storage according to the instructions printed on the kit, and making standard curves. The whole examination was performed according to the procedure on the insert kit.

This research was approved by the Komite Etik Penelitian Kesehatan (KEPK) Dr. Soetomo Hospital with ethical number 0273/KEPK/V/2018.

\section{RESULTS AND DISCUSSION}

This study used 45 serum samples of patients with a clinical diagnosis of suspected sepsis treated at the Dr. Soetomo Hospital and procalcitonin levels $>0.5$ $\mathrm{ng} / \mathrm{mL}$ irrespective of the primary diagnosis. TNF- $\alpha$ and IL- 6 levels were then measured with ELISA. The results of leukocyte count have obtained from the Laboratory Information System (LIS) data on the same day of leukocyte examination, resulting in a drop out of two patients. Leukocyte count was determined using SYSMEX XN 1000. Subjects in this study consisted of $46 \%$ male and $54 \%$ female patients, with various primary diagnoses such as stage V CKD, diabetes mellitus, aplastic anemia, CML, lung tumors, and carcinoma. The subject characteristics are shown in Table 1.

Analysis of the correlation between leukocytes, IL-6, TNF- $\alpha$ and procalcitonin using Spearman correlation test (Table 2) showed p-value $>0.05$, suggesting no significant correlation between leukocytes count, IL-6, TNF- $\alpha$ and procalcitonin levels.

Table 1. The subject characteristics

\begin{tabular}{ll}
\hline & Patients, $\mathbf{n = 4 5}$ \\
\hline Gender (\%) & \\
Male & $21(46 \%)$ \\
Female & $24(54 \%)$ \\
Age & \\
Median & 52 \\
Range & $13-85$ \\
Diagnosis & \\
Malignancy & 14 \\
CKD + DM & 8 \\
Lung disorders & 8 \\
Vascular disease & 6 \\
Others & 9 \\
Leukocytes ( / $\mathbf{m m})^{\mathbf{3}}$ & \\
Median & 16.260 \\
Range & $350-92.230$ \\
Procalcitonin (ng/mL) & \\
Median & 5.56 \\
Range & $0.54-200$ \\
Interleukin 6 (pg/mL) & \\
Mean & 29.43 \\
Median & 22.3 \\
Range & $0-73.29$ \\
TNF $\boldsymbol{\alpha}(\mathbf{p g} / \mathbf{m L})$ & \\
Median & \\
Range & $0-8$ \\
\hline
\end{tabular}

Table 2. The correlation between leukocytes, IL-6, TNF- $\alpha$, and procalcitonin

\begin{tabular}{cccc}
\hline Correlation Leukocytes & $\mathbf{n}$ & $\mathbf{r}_{\mathbf{s}}$ & P-value \\
\hline IL6 & 43 & 0.040 & 0.798 \\
TNF $\alpha$ & 43 & -0.160 & 0.304 \\
PCT & 43 & 0.154 & 0.323 \\
\hline
\end{tabular}


Analysis of the correlation between procalcitonin, IL-6, and TNF- $\alpha$ using Spearman correlation test (Table 3) showed no significant correlation between IL-6, TNF- $\alpha$ and procalcitonin ( $p>0.05)$, and $t a$ significant negative correlation between TNF- $\alpha$ and procalcitonin $(p<0.05)$.

Table 3. The correlation between procalcitonin, IL-6, and TNF- $\alpha$

\begin{tabular}{lccc}
\hline Correlation & $\mathbf{n}$ & $\mathbf{r}_{\mathbf{s}}$ & P-value \\
\hline IL6 and TNF $\alpha$ & 45 & -0 & 0.871 \\
& & .025 & \\
IL6 and PCT & 45 & 0 & 0.466 \\
& & $\begin{array}{c}.112 \\
-0\end{array}$ & 0.006 \\
TNF- $\alpha$ and PCT & 45 & .403 & \\
\hline
\end{tabular}

In this study, the diagnosis of suspected sepsis was made before the result of bacteriology cultures present. One of the biomarkers for the diagnosis of sepsis due to bacterial infection is procalcitonin; therefore, samples with procalcitonin levels $>0.5$ $\mathrm{ng} / \mathrm{mL}$ were used. Procalcitonin is a precursor of the calcitonin hormone produced parafollicular thyroid and neuroendocrine cells in the lungs and intestines. Procalcitonin secreted in response to sepsis is used as a diagnostic tool for sepsis in the United States, Europe, Australia, Asia and in several regions of Africa. ${ }^{6}$

The sepsis diagnosis in our study was established based on the quick Sepsis-Related Organ Failure Assessment (qSOFA) criteria in 2016 (high respiratory rate 22 breaths per minute, altered mental status GCS 13 , systolic arterial blood pressure $100 \mathrm{mmHg}$ ) and Systemic Inflammatory Response Syndrome (SIRS) criteria from American College of Chest Physician (ACCP) and The Society of Critical Care Medicine (SCCM) in 2001 \{ temperature $38^{\circ} \mathrm{C}$ or $36^{\circ} \mathrm{C}$, heart rate $90 \mathrm{bpm}, \mathrm{RR} 20$ breaths per minute or $\mathrm{PaCO}_{2} 32 \mathrm{mmHg}$, leukocyte count $12,000 / \mathrm{L}$ or $4000 / \mathrm{L}$ or immature (band) forms $10 \%$ added by finding the source or focus of infection)\}.

The median result of leukocytes obtained in this study was $16.260 / \mu \mathrm{L}$. There were $11(25 \%)$ septic patients with leukocyte counts $<12.000 / \mu \mathrm{L}$ and 32 (75\%) septic patients with leukocyte counts $12.000 / \mu \mathrm{L}$. The innate immune response to extracellular bacteria is particularly the mechanism of phagocytosis by neutrophils, monocytes and tissue macrophages. ${ }^{7}$ Neutrophils are phagocytic cells with the major function of detecting and engulfing microorganisms, causing increased release of leukocytes followed by immature granulocytes in sepsis. ${ }^{8,9}$

Measurement of IL- 6 levels in this study resulted in a mean value of $29.43 \mathrm{pg} / \mathrm{mL}$ with the highest levels of $73.29 \mathrm{pg} / \mathrm{mL}$ and the lowest level of $0 \mathrm{pg} / \mathrm{mL}$. IL-6 level in healthy controls was about $0-7.67 \mathrm{pg} / \mathrm{mL}$. This was consistent with the study by Pettila et al. which suggested that septic patients showed increased IL- 6 levels. ${ }^{10}$

The highest level of TNF- $\alpha$ in our study was $390.5 \mathrm{pg} / \mathrm{mL}$ and the lowest level was $0 \mathrm{pg} / \mathrm{mL}$. The median TNF- $\alpha$ level was $5.8 \mathrm{pg} / \mathrm{mL}$. TNF- levels of healthy subjects were about $0-17.66 \mathrm{pg} / \mathrm{mL}$. Previous studies showed that TNF- $\alpha$ was the primary mediator of the inflammatory response observed in septic patients and septic shock. In infection, bacterial antigens can stimulate cascade from cellular mediators and stimulate the release of cytokines such as TNF- $\alpha .{ }^{11}$

The median of the procalcitonin level in our study was $5.56 \mathrm{ng} / \mathrm{mL}$. The highest procalcitonin level in our study was $200 \mathrm{ng} / \mathrm{mL}$ and the lowest level was $0.54 \mathrm{ng} / \mathrm{mL}$. This finding was consistent with the study by Schuetz et al. which suggested that levels were increased by tens to hundreds of times in septic patients. Schuetz et al. also stated that procalcitonin levels $>0.5 \mathrm{ng} / \mathrm{mL}$ can be considered as an indicator of bacterial infections, whereas the procalcitonin levels $<0.1 \mathrm{ng} / \mathrm{mL}$ can exclude bacterial infections. ${ }^{12}$

Increased procalcitonin concentration is first detected 3-6 hours after injection of endotoxin and increased within 6 to 8 hours. Procalcitonin levels achieve their peak within 12 hours and will return to normal after 2 -3 days. Specific and rapid induction by adequate stimuli will result in high procalcitonin production in patients with severe bacterial infections or sepsis. This situation shows the pathophysiology of procalcitonin in the acute immune response. TNF- $\alpha$ increases after the entry of endotoxin and achieves its peak at 90 minutes, then followed by IL- 6 with a peak at 180 minutes. Procalcitonin increases after increase of TNF- $\alpha$ and IL-6. ${ }^{4,5}$

In this study, the statistical analysis showed no correlation between procalcitonin level with IL- 6 $(P=0.466)$, IL- 6 with TNF- $\alpha(p=0.871)$, leukocyte with IL-6 $(p=0.798)$, leukocyte with TNF- $\alpha(p=0.304)$ and leukocyte with procalcitonin $(p=0.323)$. There was no correlation between leukocyte with procalcitonin, IL- 6 , and TNF- $\alpha$, consistent with the study by Magrini et al. which found no correlation between leukocytes and procalcitonin. This was because septic patients 
have a variety of complex diseases and high comorbidities and old age. It is known that in the elderly, the WBC does not always increase, even in severe sepsis, due to the progressive aging of the bone marrow which results in a decrease of the WBC population. ${ }^{13}$ One of the four SIRS findings showed leukocyte count $>12.000 / \mathrm{mm}^{3}$ or $<4000 / \mathrm{mm}^{3}$.

The results of the statistical analysis also showed no correlation between procalcitonin with IL- 6 and IL-6 with TNF- $\alpha$. These results may be due to variations in the data of procalcitonin, IL- 6 , and TNF- $\alpha$. Another possible factor was different time of procalcitonin, IL-6, and TNF- $\alpha$ measurement when there were increased results of two parameters.

The statistical analysis showed a weak negative correlation statistically significant between TNF- $\alpha$ and procalcitonin. According to the study by Mozes et al. which determined the production and circulation levels of TNF- $\alpha$ by mononuclear cells in healthy populations using PBMC with and without endotoxin stimulation (LPS), there were significant individual variations in TNF- $\alpha$ levels. ${ }^{14}$ There were $50 \%$ of volunteers with low serum levels of TNF- $\alpha$ activity after LPS stimulation. Individual differences in the production of TNF- $\alpha$ were possibly caused by gene polymorphisms. Some cytokine gene polymorphisms are susceptible to various autoimmune infections, allergies or cardiovascular diseases. Polymorphism in the regulatory region of the cytokine gene is associated with high and low cytokine production. ${ }^{15}$

The synthesis of procalcitoninis caused by TNF- $\alpha$ or IL-6, the two major cytokines in inflammation cascade because they always reach the peak level before procalcitonin. This is consistent with the Dahaba study which investigated the role of procalcitonin in sepsis cascade. Procalcitonin injection did not initiate or increase TNF- $\alpha$ production, in healthy animals and sepsis cases; however, injection of TNF- $\alpha$ was able to induce and increase procalcitonin level. It indicated that the release of procalcitonin was not the beginning but an intermediate event in the sepsis cascade that required an inflammatory background to exert its effects. ${ }^{16}$

Endotoxin from the outer membrane of Gram-negative bacteria strongly stimulates human monocytes to release IL-1, TNF- $\alpha$, and PGE2 which induce biological responses in the body's homeostatic mechanism. It has been reported that monocytes can be treated in-vitro without spontaneous activation of monokine secretion, but very low concentrations of LPS can induce the secretion of IL-1, TNF- $\alpha$ and PGE2 from human monocytes, indicating that IL- 1 , TNF- $\alpha$ secretion and TNF- $\alpha-P G E 2$ correlates strongly and inter individual differences occur in monokine and PGE2 secretion. TNF levels and activity are also regulated by other cytokines. The metabolism of cyclo-oxygenase such as PGE2 has been shown to inhibit TNF-a production at high concentrations. ${ }^{14}$

This study had various clinical diagnosis conditions, resulting in various TNF- $\alpha$ production which caused a negative correlation with procalcitonin. The increase of the procalcitonin level in our study was not able to be determined by the presence of Gram-negative bacterial infection because the culture was not performed.

The study by Mueller et al. showed that procalcitonin had different profiles from the other sepsis marker such as CRP, lactate or various proinflammatory cytokine (IL-6, IL-8) because it belongs to a different class of molecules, known as hormokines which possess cytokine-like nature from procalcitonin during inflammation and infection. ${ }^{17,18}$ Procalcitonin is also a natural substrate for dipeptidyl peptidase IV, which can inactivate various cytokines. ${ }^{15}$ The specificity for bacterial-induced sepsis is low in cytokines but cytokines immediately react to severe systemic inflammation, cytokines also increase in local effusions and are generally not seen in procalcitonin. Proinflammatory cytokines are also less specific and peak levels can change rapidly without clinical correlation. ${ }^{15}$

\section{CONCLUSIONS AND SUGGESTIONS}

There was a significant negative correlation between procalcitonin and TNF- $\alpha$. This study showed that procalcitonin was unable to represent the inflammatory status of patients with suspected sepsis.

This study was an initial study which analyzed the correlation of procalcitonin levels with TNF- $\alpha$, interleukin-6, and leukocytes; therefore, further research with homogeneity of the basic clinical conditions, the severity of sepsis, and culture results of septic patients to produce more reliable results. Homogeneity is required for the measurement of procalcitonin, TNF- $\alpha$, and interleukin- 6 levels to enable serial comparison.

\section{REFERENCES}

1. Ashitha L, Vijayan, Vanimaya, Ravindran S, Saikant R, et al. Procalcitonin: A promising diagnostic marker for sepsis and antibiotic therapy. Journal of Intensive Care, 2017; 5(51): 1-7. 
2. Pugin J, Meisner M, Leon A, Gendrel D, Lopez AF. Guide for the clinical use of Procalcitonin $(P C T)$.Thermo Fisher Scientific Inc. www. thermoscientific.com. Edisi 10., 2011; 12(2012): 1-23.

3. Riedel S, Melendez JH, An AT, Rosenbaum JE, Zenilman JM. Procalcitonin as a marker for the detection of bacteremia and sepsis in the Emergency Department. American Society for Clinical Pathology, 2011; 135(2): 182-189.

4. Muller B, Becker KL, Schachinger $H$, Rickenbacher PR, Huber $\mathrm{PR}$, et al. Calcitonin precursors are reliable markers for sepsis in a medical intensive care unit. Crit Care Med, 2000; 28: 977-983.

5. Correia JW, Freitas MV, Querioz JA, Perrin MP, Cavadas B. Interleukin-6 blood levels insensitive and multiresistant tuberculosis. Infection, 2009; 37 : 138-141.

6. Lloyd MM, Kuyl JM. Comparison of three methods for procalcitonin analysis. Med Tech, 2012; 26(1):48-51.

7. Arifijanto MV. Sepsis. In A. Tjokropprawiro A, et al. eds. Buku Ajar Ilmu Penyakit Dalam. $2^{\text {nd }}$ Ed., Surabaya, Airlangga University Press, 2015; 701-707.

8. Ma'at, Suprapto. Inflamasi. Edisi 1., Surabaya, Pusat Penerbitan dan Percetakan UNAIR (AUP), 2012; 18.

9. Stearns-Kurosawa DJ, Osuchowski MF, Valentine C, Kurosawa S, Remick DG. The pathogenesis of sepsis. Annual Review of Pathology Mechanisms of Disease, 2011; 6: 19-48.

10. Pettila V, Hynninen M, Takkunen O, Kuusela $P$, Valtonen M. Predictive value of procalcitonin and interleukin 6 in critically ill patients with suspected sepsis. Intensive Care Med, 2002; 28: 1220-1225.

11. Spooner E C, Markowitz PN, Sarawlatz PL. The role of tumor necrosis factor in sepsis. Journal Immunology and Immunopathology, 1992; 62: S11-S17.

12. Schuetz P, Chiappa V, Briel M, Greenwald JL. Procalcitonin algorithms for antibiotic therapy decisions. Arch Intern Med, 2011; 171(15): 1322-1331.

13. Magrini L, Gagliano G, Travaglino F, Vetrone F, Marino $\mathrm{R}$, et al. Comparison between white blood cell count, procalcitonin and $C$ reactive protein as diagnostic and prognostic biomarkers of infection or sepsis in patients presenting to the emergency department. Clin Chem Lab Med, 2014; 52(10): 1465-1472.

14. Mozes T, Barath I, Gornicsar K, Grosz A, Gondocs CS, et al. Deviations in circulating TNF- $\alpha$ levels and TNF- $\alpha$ production by mononuclear cells in healthy human populations. Hindawi Mediators of inflammation, 2011; 1-8.

15. Müller B, Becker KL. Procalcitonin: How a hormone became a marker and mediator of sepsis. Swiss Med Wkly, 2001; 131(41-42): 595-602.

16. Dahaba AA, Metzier H. Procalcitonin's role in the sepsis cascade. Is procalcitonin a sepsis marker or mediator? Minerva Anaesthesiol, 2009;75(7-8): 447-52.

17. Wrenger S, Kahne T, Bohoun C, Weglohner W, Ansorge $\mathrm{S}$, et al. Amino-terminal truncation of procalcitonin, a marker for systemic bacterial infections, by dipeptidyl peptidase IV (DP IV), FEBS letters, 2000; 466(1): 155-9.

18. van Langevelde $P$, Joop $K$, van Loon J, Frölich $M$, Groeneveld $\mathrm{PH}$, et al. Endotoxin, cytokines, and procalcitonin in febrile patients admitted to the hospital: Identification of subjects at high risk of mortality. J T Clin Infect Dis, 2000; 31(6): 1343-8. 